\title{
EVALUATION OF ANAEMIA IN PATIENTS AGED 55 YEARS AND ABOVE IN A TERTIARY CARE SETTING IN NORTH KERALA
}

\author{
Thundiparambil Raghavan Nisha1, Gopalan Nair Rajan², Prasad PH ${ }^{3}$
}

${ }^{1}$ Assistant Professor, Department of Pathology, Government Medical College, Kozhikode.

${ }^{2}$ Additional Professor, Department of Pathology, Government Medical College, Kozhikode.

${ }^{3}$ Professor, Department of Pathology, Government Medical College, Thrissur.

\section{ABSTRACT}

\section{BACKGROUND}

Even though ageing is considered as a natural process, various complex impairments and diseases can occur in many elderly people. Anaemia is common in elderly and its prevalence increases with age. In elderly population, anaemia is not to be considered as an age related change, as anaemia can never be a normal physiological phenomenon. There is an increased incidence of morbidity and mortality in patients with anaemia. In order to highlight this problem, we evaluated anaemia in elderly population coming to clinical pathology department for various medical ailments.

\section{MATERIALS AND METHODS}

After taking informed written consent, patients were subjected to a detailed history, thorough clinical examination and various relevant investigations including bone marrow examination, radiological studies and endoscopic biopsies.

\section{RESULTS}

Out of the 1000 patients, 644 patients were male and 366 patients were female. Maximum number of patients (440) were in the age group 60-69 years. 500 cases were evaluated for the cause of anaemia. Among all the patients (irrespective of age groups and types of anaemia), anaemia of chronic disease was found to be most common (48.9) followed by nutritional anaemia (19.1\%), and malignancies and haemorrhage.

\section{CONCLUSION}

Prevalence of anaemia is very high in our population compared to other studies. It is important that older persons with anaemia receive adequate attention in clinical practice and not to be considered as a part of normal ageing. This study clearly points out the significance of detailed investigations in these patients.

\section{KEYWORDS}

Anaemia, Elderly, Haemoglobin, Chronic Disease, Malignancies.

HOW TO CITE THIS ARTICLE: Nisha TR, Rajan GN, Prasad PH. Evaluation of anaemia in patients aged 55 years and above in a tertiary care setting in North Kerala. J. Evolution Med. Dent. Sci. 2017;6(48):3694-3697, DOI: 10.14260/Jemds/2017/797

\section{BACKGROUND}

Anaemia is common in elderly and its prevalence increases with age. According to World Health Organization criteria (Hb less than $12 \mathrm{~g} / \mathrm{dL}$ in women and less than $13.5 \mathrm{~g} / \mathrm{dL}$ in men), the prevalence of anaemia in the elderly ranged from 8$45 \%$ with the highest prevalence in men aged 85 years or older. $1,2,3$

The increased incidence of anaemia with ageing has led to speculation that lower $\mathrm{Hb}$ levels may be a normal consequence of ageing. But most of the older people maintain a normal red cell count, $\mathrm{Hb}$ and haematocrit and in most elderly patients with anaemia an underlying cause is found. There are studies pointing out that anaemia has an effect in survival of these patients. Their survival rates are definitely lower than normal controls. ${ }^{4,5,6}$

In our study, we are estimating the prevalence of anaemia in patients above 55 years and on evaluating the causes of

Financial or Other, Competing Interest: None.

Submission 02-04-2017, Peer Review 03-06-2017,

Acceptance 09-06-2017, Published 15-06-2017.

Corresponding Author:

Dr. Thundiparambil Raghavan Nisha,

32/1145 B, Naduthodiyil,

Viruppil, Chelavoor P. O, Calicut.

E-mail: nisshaanandan@gmail.com

DOI: $10.14260 /$ jemds $/ 2017 / 797$ anaemia, the most common causes of anaemia in older age group are anaemia of chronic disease, nutritional anaemia, post haemorrhagic anaemias and malignancies. Prevalence of anaemia is very high in our study compared to others. Also, higher prevalence is seen in low socioeconomic group.

\section{Objectives}

1. To estimate the prevalence of anaemia in patients aged 55 years and above coming to clinical pathology for routine investigations.

2. To evaluate the causes of anaemia in patients aged 55 years and above coming to clinical pathology.

\section{MATERIALS AND METHODS}

\section{Subjects}

1. 1000 consecutive patients who came to clinical pathology for routine investigations were analysed for assessing the overall prevalence of anaemia.

2. 1045 consecutive patients aged 55 years and above who came to clinical pathology were analysed for assessing the overall prevalence of anaemia in this age group.

3. 508 cases of anaemia in patients aged 55 years and above were investigated to find out the cause of anaemia. 
Definition of anaemia was as per WHO criteria i.e.; $<12$ $\mathrm{g} \%$ in females and $>13.5 \mathrm{~g} \%$ in males.

History regarding dietary habit, bleeding manifestations or chronic blood loss, drug intake, any associated morbidities or weight loss, any history of alcoholism were recorded. Investigations included complete blood count, peripheral smear, and routine biochemistry including renal function tests, stool occult blood, bone marrow examination and bone marrow iron stores. Necessary investigations like endoscopy for gastrointestinal bleeding, serum electrophoresis for multiple myeloma, etc. were done in relevant cases.

Statistical Analysis was done with SPSS 10 statistical package. Difference in proportions were checked by the Chi square test.

\section{RESULTS}

1000 consecutive cases were analysed to assess the prevalence of anaemia, 640 cases (64\%) had anaemia with a mean $\mathrm{Hb}$ value of $11.6 \mathrm{~g} / \mathrm{dL}$. Females were more affected than males.

Out of 1000 elderly study subjects, 826 (82.6\%) patients had anaemia. $18.3 \%$ were in the age group of $55-59,44 \%$ were in the age group of $60-69$ years, followed by $26.8 \%$ in 70-79 years, $10.9 \%$ in 80 years and above. The prevalence of anaemia in these age group is given in Table 1. Maximum number of elderly (68.8\%) had mild type of anaemia, also $26.3 \%$ had moderate and $4.9 \%$ had severe anaemia. Males (82.8) were more affected than females (71.8\%) (Figure 1). The prevalence of anaemia was $71 \%$ in above poverty line and $82 \%$ in below poverty line. This was statistically significant. But there was no significant difference in iron deficiency anaemia in above poverty line and below poverty line patients, both $6.8 \%$.

500 cases were evaluated for causes of anaemia, as shown in Table 1 anaemia of chronic disease was the most common pathology, whereas malignancies and nutritional anaemias were also present in a significant proportion of cases. There were only 97 cases $(19.1 \%)$ of nutritional anaemia of which majority was iron deficiency anaemia 71 (12.2\%).

\section{DISCUSSION}

Anaemia is a common condition in older population, and the prevalence of anaemia rises with advancing age. Although it was previously believed that decline in haemoglobin level might be a normal consequence of ageing, evidence has accumulated that anaemia does reflect poor health and increased vulnerability to adverse outcomes in older persons. It is associated with an increased mortality and morbidity and a reduced quality of life. The mortality risk has been found to be increasing with decrease in haemoglobin values. ${ }^{7}$ Decrease in haemoglobin may be a clue to the underlying cause, therefore, all persons presenting with anaemia should be investigated to find out the underlying cause even if there is mild anaemia. Many studies have been done in different parts of the world regarding the prevalence of anaemia, the evaluation of its causes and outcome. But so far, no such studies have been done regarding this in Kerala. In this study, we have tried to evaluate the causes of anaemia in patients aged 55 years and above.
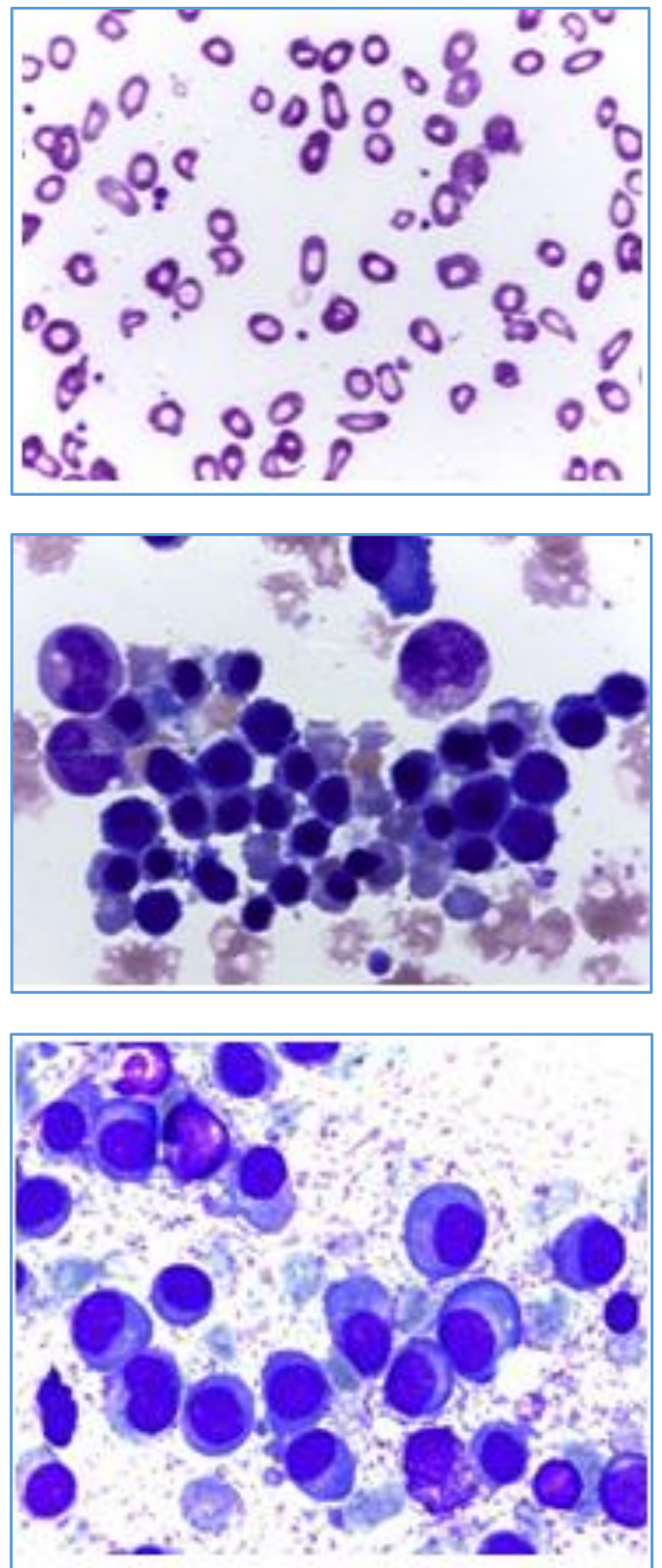

Figure 1. A) Microcytic Hypochromic Blood Picture B) Megaloblastic Erythroid Series C) Multiple Myeloma

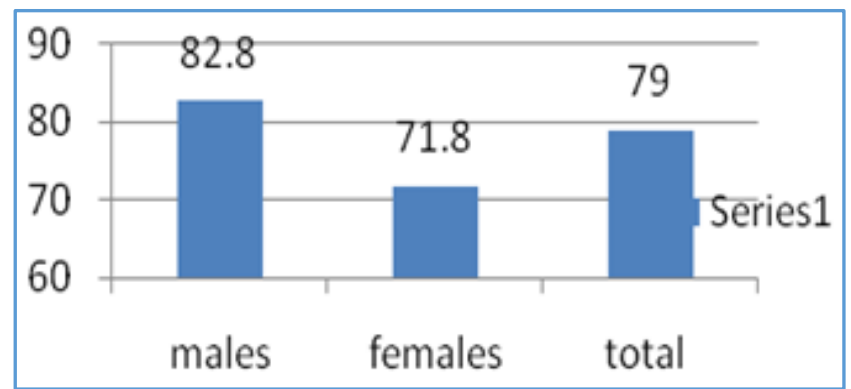

Chi square $=8.0 \mathrm{p}=0.046$

Figure 2. Prevalence of Anaemia According to Sex 


\begin{tabular}{|c|c|c|}
\hline Group & n & Percentage \\
\hline Acute leukaemia & 40 & 7.9 \\
\hline Chronic diseases & 219 & 48.9 \\
\hline $\begin{array}{c}\text { Chronic leukaemia and } \\
\text { Lymphoma }\end{array}$ & 49 & 9.7 \\
\hline $\begin{array}{c}\text { Post haemorrhagic } \\
\text { Nutritional anaemia }\end{array}$ & 43 & 8.5 \\
\hline $\begin{array}{c}\text { Other haematological } \\
\text { disorders** }\end{array}$ & 6 & 19.1 \\
\hline Other diseases & 50 & 5.9 \\
\hline Total & $\mathbf{5 0 8}$ & $\mathbf{1 0 0}$ \\
\hline Table 1. Causes of Anaemia \\
\hline
\end{tabular}

*chronic blood loss in GI bleed and malignancies **MDS, Aplastic anaemia, Myeloma

\begin{tabular}{|c|c|c|}
\hline Diagnosis & $\begin{array}{c}\text { Joosten } \\
\text { et al (\%) }\end{array}$ & $\begin{array}{c}\text { Present } \\
\text { Study (\%) }\end{array}$ \\
\hline Anaemia & 24 & 82.6 \\
\hline $\begin{array}{c}\text { Anaemia of chronic } \\
\text { disease }\end{array}$ & 34 & 48.9 \\
\hline Nutritional anaemia & 20.6 & 19.1 \\
\hline Post haemorrhagic & 7.3 & 8.5 \\
\hline MDS \& acute leukaemia & 5.6 & 7.9 \\
\hline $\begin{array}{c}\text { Chronic } \\
\text { leukaemia/lymphomas }\end{array}$ & 5.1 & 9.7 \\
\hline $\begin{array}{c}\text { Other haematological } \\
\text { disorders }\end{array}$ & 2.8 & 5 \\
\hline \multicolumn{2}{|c|}{ Table 2. Comparison with the Study by Joosten et al (1992) } \\
\hline
\end{tabular}

\section{Prevalence of Anaemia in Patients}

There is higher prevalence of anaemia in this study, compared to the other studies. The overall prevalence of anaemia of patients of all age groups coming to our clinical pathology lab was $64 \%$. This high prevalence could be due to the study population being hospitalised patients and hence not a normal population. Females are more anaemic than males in younger age groups. This might be due to the menstrual loss and inadequate food intake in females.

The prevalence of anaemia in the elderly population was also very high (79\%) in our study compared to others. ${ }^{8,9,10}$ This could be explained by the reason that ours being a hospital based study rather than being a community based study. But even after making allowances for these factors, there is definitely an increase in incidence of anaemia. This might be a reflection of the nutritional status of the elderly population. Both the degree of anaemia and prevalence of anaemia are increasing with age.11 There was also a significant difference between mean $\mathrm{Hb}$ in the male and female population. The degree of anaemia and prevalence of anaemia was more in males when compared to females. The dataset being from hospitalised patients, this might be a reflection of higher occurrence of chronic diseases and gastrointestinal malignancies in males compared to females (Figure 2). Both in males and females, the prevalence of anaemia rises with age. In males, it ranged from $75-83 \%$ whereas in females it ranged from $55-100 \%$.

There was a significant difference in the $\mathrm{Hb}$ values between patients belonging to different economic status. The prevalence is more in those below poverty line. Prevalence of anaemia is $82 \%$ in below poverty line and $71 \%$ in above poverty line. This was statistically significant. Nutritional intake may be an important cause for the difference.

Another important observation was that even though the prevalence of anaemia was higher in our study the percentage of nutritional anaemia was in only $6.8 \%$ and there was no difference in the incidence of nutritional anaemia among above poverty line and below poverty line. There was no significant difference in incidence of nutritional anaemia between males and females either. The rather low prevalence of nutritional anaemia even among elderly is intoned with the overall socioeconomic development that has occurred in Kerala in the last decades. But it is to be remembered that these figures pertain only to anaemias solely due to nutritional causes. This will not include anaemia due to other causes.

A comparison of the various studies in the elderly showing the prevalence of anaemia is shown in the table 2 .

The prevalence of anaemia is higher in our studies compared to all other studies in the elderly. This applies to other hospital based studies like Bird et al (Males 51\% and female $41 \%$ ), Joosten et $\mathrm{al}^{9,10}$ (Males $61 \%$ and females $31 \%$ ) though the differences in the $\mathrm{Hb}$ values in different populations is due to the difference in nutritional intake rather than due to racial predisposition. Hence, the difference can only be explained by the same. Fortunately, most cases of anaemia were mild even in this elderly population. About $70 \%$ mild anaemia, $25 \%$ moderate and only $5 \%$ accounted for severe anaemia (Graded mild if $\mathrm{Hb}$ was more than $10 \mathrm{~g} \%$, moderate if $\mathrm{Hb}$ was between 7 and 10, severe if less than 7). This picture was the same in above and below the poverty line. There was also no change with increasing age.

\section{Evaluation of the Causes for Anaemia}

The most common case of anaemia in this study was anaemia of chronic diseases ${ }^{12}$ (Other than malignancies), followed by malignancies. Nutritional anaemia came third in the list. This could be due to the fact that ours being a referral hospital and many of our cases were referred cases, thus accounting for higher proportion of malignancies in our data. Again, the percentages of pure nutritional anaemias were lower, probably because most of the nutritional anaemias might have been treated in the peripheral health care systems.

Evaluation of causes of anaemia according to the grade showed higher proportion of severe anaemia in disease groups like post haemorrhagic (Mostly gastrointestinal malignancy), nutritional and acute leukaemia. In disease groups like chronic diseases and chronic leukaemia, mild and moderate anaemia predominated.

Average $\mathrm{Hb}$ values among the disease group showed lowest values in the group which include haemolytic anaemia, MDS and aplastic anaemia. Highest values were observed in anaemia of chronic diseases.

Evaluation of haematocrit values, MCV, $\mathrm{MCH}$ and $\mathrm{MCHC}$ among the disease groups showed that it was lowest among the groups of nutritional anaemia and post haemorrhagic as expected, whereas the red cell distribution width was increased in the same.

\section{Understanding the Impact of Anaemia}

Several studies have demonstrated poorer outcomes in older persons with anaemia, including mild anaemia, than in nonanaemic persons of the same age. In persons of all ages with 
specific diseases, amelioration of anaemia has been shown to have a beneficial impact on morbidity and mortality. It is important that anaemia in older persons receive adequate attention in clinical practice and not be considered simply a normal part of age. This study clearly points out the significance of detailed investigation of symptomatic anaemia, as in most of them an identifiable pathology would be present.

\section{CONCLUSION}

Our study concluded that anaemia of chronic disease is the most common type of anaemia in elderly individuals, but all other types are also seen in different proportions. Chronic disease was responsible for more cases of anaemia even than nutritional anaemia. However, evaluation of the aetiology and correction of anaemia is very critical irrespective of age group and one should not consider anaemia a natural consequence of ageing.

\section{REFERENCES}

[1] Anía BJ, Suman VJ, Fairbanks VF, et al. Prevalence of anemia in medical practice: community versus referral patients. Mayo Clin Proc 1994;69(8):730-5.

[2] Van Puyvelde K, Cytryn E, Mets T, et al. Anaemia in the elderly. Acta Clin Belg 2009;64(4):292-302.

[3] Juárez-Cedillo T, Basurto-Acevedo L, Vega-García S, et al. Prevalence of anemia and its impact on the state of frailty in elderly people living in the community: SADEM study. Ann Hematol 2014;93(12):2057-62.

[4] Salive ME, Cornoni-Huntley J, Guralnik JM, et al. Anemia and hemoglobin levels in older persons: relationship with age, gender, and health status. J Am Geriatr Soc 1992;40(5):489-96.
[5] Guralnik JM, Ershler WB, Schrier SL, et al. Anemia in the elderly: a public health crisis in hematology. Hematology Am Soc Hematol Educ Program 2005:528-32.

[6] Zakai NA, Katz R, Hirsch C, et al. A prospective study of anemia status, hemoglobin concentration, and mortality in an elderly cohort: the cardiovascular health study. Arch Intern Med 2005;165(19):2214-20.

[7] Kikuchi M, Inagaki T, Shinagawa N. Five-year survival of older people with anemia: variation with hemoglobin concentration. J Am Geriatr Soc 2001;49(9):1226-8.

[8] Zilinski J, Zillmann R, Becker I, et al. Prevalence of anemia among elderly inpatients and its association with multidimensional loss of function. Ann Hematol 2014;93(10):1645-54.

[9] Ferrucci L, Guralnik JM, Bandinelli S, et al. Unexplained anaemia in older persons is characterised by low erythropoietin and low levels of pro-inflammatory markers. $\mathrm{Br} \mathrm{J}$ Haematol 2007;136(6):849-55.

[10] Joosten E, Pelemans W, Hiele M, et al. Prevalence and causes of anaemia in a geriatric hospitalized population. Gerontology 1992;38(1-2):111-7.

[11] Beghé C, Wilson A, Ershler WB. Prevalence and outcomes of anemia in geriatrics: a systematic review of the literature. Am J Med 2004;116 Suppl 7A:3S-10S.

[12] Benoist BD, McLean Erin, Egillnes, et al. Worldwide prevalence of anemia 1993-2005: WHO Global Database on Anemia, Spain: WHO, 2008. 